\title{
P I 7- I 9. Impact of single epitope-specific CD8+ T cell memory induction by prophylactic vaccination on immunodeficiency virus control
}

\author{
T Tsukamoto* and T Matano
}

\begin{abstract}
Address: Division of Microbial Infection, Institute of Medical Science, University of Tokyo, Tokyo, Japan
\end{abstract}
* Corresponding author

from AIDS Vaccine 2009

Paris, France. 19-22 October 2009

Published: 22 October 2009

Retrovirology 2009, 6(Suppl 3):P30I doi:I0.II86/I742-4690-6-S3-P30 I

This abstract is available from: http://www.retrovirology.com/content/6/S3/P30I

(C) 2009 Tsukamoto and Matano; licensee BioMed Central Ltd.

\section{Background}

Despite many efforts to develop AIDS vaccines eliciting Tcell responses, whether this approach actually results in HIV control remains unknown. It is important to determine which T-cell responses to be induced by prophylactic vaccination for HIV control after virus exposure. Virusspecific CD8+ T cells are crucial for HIV control, but the real benefit of their memory induction has not been evaluated. Here, we examined the efficacy of a prophylactic vaccine eliciting single Gag241-249 epitope-specific CD8+ T-cell responses against simian immunodeficiency virus (SIV) challenge in macaques.

\section{Methods}

We developed a prophylactic vaccine using a Sendai virus vector expressing a single, Mamu-A*90120-5-restricted Gag241-249 CTL epitope fused with EGFP protein. Eighteen Burmese rhesus macaques possessing this MHC-I allele (Mamu-A*90120-5) were divided into three groups of six animals each. Group I received no vaccination, group II a control vaccine expressing EGFP, and group III a vaccine expressing Gag241-249-EGFP fusion protein. All these three groups were challenged intravenously with SIVmac239.

\section{Results}

The vaccination resulted in induction of Gag241-249-specific CD8+ T-cell responses in group III animals. After SIV challenge, these vaccinees exhibited significantly reduced peak viral loads, followed by SIV containment at the set- point. In the acute phase, these animals showed dominant Gag241-249-specific CD8+ T-cell responses with higher effector memory frequencies.

\section{Conclusion}

These results demonstrate that single epitope-specific memory CD8+ T cells induced by vaccination could indeed facilitate SIV control after virus exposure, indicating the rationale of a prophylactic vaccine strategy eliciting virus-specific CD8+ T-cell memory for HIV control. 